\title{
The antimicrobial effect of colistin methanesulfonate on Mycobacterium tuberculosis in vitro
}

Shane Vontelin van Breda ${ }^{\mathrm{a}, *}$, Antoinette Buys ${ }^{\mathrm{b}, 1}$, Zeno Apostolides ${ }^{\mathrm{c}, 2}$, Edward Anthony Nardell ${ }^{\mathrm{d}, 4}$, Anton Carel Stoltz ${ }^{\mathrm{a}, 3}$

${ }^{a}$ Department of Internal Medicine, Division of Infectious Diseases, ${ }^{b}$ Laboratory for Microscopy and Microanalysis, ${ }^{\mathrm{c}}$ Department of Biochemistry, University of Pretoria, Pretoria, South Africa; ${ }^{\mathrm{d}}$ Division of Global Health Equity, Brigham \& Women's Hospital, Division of Global Health Equity, Boston, USA

E-mail addresses: antoinette.buys@up.ac.za (A. Buys); zeno.apostolides@up.ac.za (Z. Apostolides); enardell@gmail.com (E.A. Nardell); anton.stoltz@up.ac.za (A.C. Stoltz)

Postal addresses: ${ }^{1}$ University of Pretoria, Laboratory for Microscopy and Microanalysis, Private Bag X20, Hatfield 0028, South Africa (A. Buys); ${ }^{2}$ University of Pretoria, Department of Biochemistry, Private Bag X20, Hatfield 0028, South Africa (Z. Apostolides); ${ }^{3}$ University of Pretoria, Steve Biko Academic Hospital, Department of Internal Medicine, Division of Infectious Diseases, Private Bag X20, Hatfield 0028, South Africa (A.C. Stoltz); ${ }^{4}$ Brigham \& Women's Hospital, Division of Global Health Equity, Partners In Health, 641 Huntington Avenue, 3A-03, Boston, MA 02115, USA

"Corresponding author. University of Pretoria, Steve Biko Academic Hospital, Department of Internal Medicine, Division of Infectious Diseases, Private Bag X20, Hatfield 0028, South Africa. Tel.: +27 12354 4961; fax: +27 086656 3033; E-mail address: shane.vontelin.van.breda@ gmail.com

Please cite this article in press as: van Breda SV, et al., The antimicrobial effect of colistin methanesulfonate on Mycobacterium tuberculosis in vitro, Tuberculosis (2015), http://dx.doi.org/10.1016/j.tube.2015.05.005

\section{SUMMARY}

Polymyxins have previously been described to have activity against M. tuberculosis (MTB), but further research was abandoned due to systemic toxicity concerns to achieve the required MIC. Colistin methanesulfonate (CMS), a polymyxin, is well tolerated when inhaled directly into the lungs, resulting in high local concentrations. We report here for the first time, MIC and MBC data for CMS determined by the microtiter Alamar Blue assay (MABA). We also determined how the MIC would be affected by the presence of pulmonary surfactant (PS) and if any synergy with 
isoniazid (INH) and rifampicin (RIF) exists. The effect of CMS on the ultrastructure of MTB was also determined. The MIC for CMS was $16 \mathrm{mg} / \mathrm{L}$, while the MBC was $256 \mathrm{mg} / \mathrm{L}$. MIC for CMS in PS was antagonised by eight fold. For synergy, indifference was determined while time-kill assays revealed a greater killing effect when CMS was used together with INH. Ultrastructure analysis suggests that the disruption of the outer polysaccharide layer of MTB by CMS may lead to enhanced uptake of INH. Our findings may provide insight for further investigations of CMS against MTB.

Keywords: Tuberculosis, colistin methanesulfonate, colistin sulfate, polymyxin, selfpromoted uptake

\section{Introduction}

One of the world's top infectious killers is tuberculosis (TB) and it remains the leading killer of people living with HIV [1]. Currently in the late phase of clinical development are ten new or re-purposed anti-TB drugs, with two new drugs being approved for MDR-TB treatment under specific conditions [2]. Investigating the use of 'off the shelf' antimicrobials, that have anti-TB potential and alternative delivery routes i.e., inhalation, could eventually lead to improved treatment success. One such class of 'off the shelf' antimicrobial is colistin (polymyxin).

Polymyxins were first isolated in 1947 [3] but only polymyxin B, and E (colistin sulfate $(\mathrm{CST}))[4,5]$ are used clinically [6]. Polymyxin B sulfate (PB) and CST are cationic at physiological pH. PB and CST are described as having amino acids (D and L) arranged to form a cyclic heptapeptide ring, with a tripeptide side chain covalently bound to a fatty acid moiety [6]. While PB is administered parenterally as such, CST is administered parenterally in the form of CMS, in which methanesulfonate moieties are attached through covalent bonds to the primary amines present on the amino acids [6]. In contrast to PB and CST, CMS is negatively charged at physiological $\mathrm{pH}$, and is readily converted to colistin in microbiological broth [7], and in vivo $[8,9]$.

Polymyxins disrupt the membranes of gram-negative bacteria by displacing divalent 
cations [10] and interacting with the lipid components, and the cytoplasmic membrane $[11,12]$. This leads to cell death, due to enhanced permeability of the membranes. Since polymyxins retain activity against gram-negative bacteria when resistance to other drugs develop, PB and CMS are being used as last-line therapies to treat gram-negative MDR bacterial infections. Treatment occurs often in critical care units, and many informative reviews on polymyxins exist [13-17].

CMS can be administered via inhalation and has been used extensively to treat gramnegative bacterial infections in cystic fibrosis patients, other critically ill patients with MDR Acinetobacter baumannii or Pseudomonas aeruginosa nosocomial pulmonary infections [6]. This method of administration might be advantageous for MTB treatment since high local concentrations could presumably be achieved. In addition to a therapeutic affect, this might help control MTB transmission in the hospital, clinic, community and home, since the organisms are believed to be aerosolised from the proximal airways by cough.

Broad antimycobacterial activity for CST has been known since 1986, but the drug has never been used systemically for TB. This is due to high MIC and systemic toxicity concerns. Many publications exist that investigate the effects of polymyxins on Mycobacteria [18-25]. The most significant publication determined that the MIC and MBC values for CST against MTB were $5 \mathrm{mg} / \mathrm{L}$ and $50 \mathrm{mg} / \mathrm{L}$ respectively, as determined by broth dilution and by out-plating appropriate dilutions onto Löwenstein-Jensen media [20]. Considering the fact that the authors [20] focused on CST and its relation to parenteral administration and its systemic toxicity concerns, investigating the less toxic CMS, that can be administered via inhalation, minimising systemic exposure, is a research topic that will add much value.

The aim of this publication was (1) to explore the MIC and MBC of CMS using the MABA, (2) to understand how PS would effect CMS MIC, (3) to determine if any interaction between CMS, INH and RIF exists by synergy and time-kill studies, (4) followed by studying the ultrastructure affects of CMS on MTB. 


\section{Material and methods}

\subsection{Preparation of strain and working stocks}

MTB H37Ra ATCC 25177 was obtained from Ampath Pathology Laboratory Support Services (Centurion, Gauteng, South Africa). The strain was swabbed onto Middlebrook 7H10 agar (Becton Dickinson, Woodmead, Gauteng, South Africa), supplemented with $0.5 \%$ v/v glycerol (Saarchem, Krugersdorp, Gauteng, South Africa), and enriched with $10 \%$ v/v oleic acid, albumin, dextrose, catalase (OADC) (Becton Dickinson). After three weeks of incubation at $37^{\circ} \mathrm{C}$, a cell suspension of McFarland 3 was prepared in 1 x PBS (Sigma-Aldrich, Kempton Park, Gauteng, South Africa) containing $0.05 \%$ v/v Tween 80 (Saarchem). Aliquots of $1 \mathrm{ml}$ were stored at $-80^{\circ} \mathrm{C}$ in cryovials, containing $20 \% \mathrm{v} / \mathrm{v}$ glycerol (Saarchem). Presence of MTB was confirmed by using the TB Ag MPT64 Device (KAT Medical, Roodepoort, Gauteng, South Africa) and purity was determined by swabbing $100 \mu \mathrm{l}$ of culture media onto tryptic soy agar (Merck, Darmstadt, Germany), and incubating at $37^{\circ} \mathrm{C}$ for 24 to 48 hours. Additionally, the strain was tested using Mycobacterium CM/AS, MTBC and MTBDRplus assays (Hain Life-Science, Nehren, Germany). Before MIC and MBC investigations, a cryovial of the stored aliquot was allowed to thaw to room temperature, was vortexed and swabbed onto Middlebrook 7H10 agar. Plates were sealed in Ziploc bags and incubated at $37^{\circ} \mathrm{C}$ until mid-log growth was reached.

\subsection{Antimicrobials}

All antimicrobials used were prepared fresh on the day of experimentation. INH and RIF were included as controls. All stock solutions were dissolved in $\mathrm{dH}_{2} \mathrm{O}$ ( $\mathrm{RIF}$ was dissolved in DMSO (Sigma-Aldrich)), filter sterilised using $0.2 \mu \mathrm{m}$ filters (except for polymyxins; due to possible interactions with the filter membrane) and further diluted in $\mathrm{dH}_{2} \mathrm{O}$. For polymyxins, all dilutions were prepared using Eppendorf (Hamburg, Germany) Protein LoBind tubes. 
Sauton liquid medium was used as the test media to better control parameters and avoid false polymyxin MIC and MBC. The media was prepared as previously described [26]; glycerol was substituted with $0.2 \% \mathrm{w} / \mathrm{v}$ glucose (Saarchem) to avoid the possibility of lower than normal MICs due to glycerol dependence [27], cationadjusted to provide $\mathrm{Mg}^{2+}(10-12.5 \mathrm{mg} / \mathrm{L})$ and $\mathrm{Ca}^{2+}(20-25 \mathrm{mg} / \mathrm{L})$, and supplemented with $0.05 \% \mathrm{v} / \mathrm{v}$ Tween 80 . No enhanced effect of Tween 80 with polymyxins against Mycobacteria was previously reported [20]. MABA was adopted from previously established protocols [28, 29]. Sterile polypropylene, flat bottomed, 96well microtiter plates with lids were used (Eppendorf). Using a mid-log culture grown from a stored aliquot (2.1), a McFarland 1 cell suspension was prepared using $1 \mathrm{x}$ PBS containing $0.05 \% \mathrm{v} / \mathrm{v}$ Tween 80 and adjusted using a spectrophotometer. A 1:25 dilution of the cell suspension was made using Sauton media. Next, $250 \mu \mathrm{l}$ $\mathrm{dH}_{2} \mathrm{O}$ was added to the outer perimeter wells to prevent evaporation of the media from the test wells. In row B, columns 2-11, $195 \mu$ media was added while $100 \mu \mathrm{l}$ of the media was added to the rest of the test wells. The final concentration of the antimicrobials tested was as follows: INH (Merck): 0.016-0.256 mg/L, RIF (EMD Millipore, Billerica, MA, USA): 0.0016-0.0256 mg/L, CST ( $\geq 15000$ U/mg)(SigmaAldrich) and CMS (12500 IU/mg) (Sanofi-Aventis, Midrand, Gauteng, South Africa): 2-32 mg/L. Antimicrobials ( $5 \mu \mathrm{l}$ ) were added to row B, column 2-11 and serially diluted using a multichannel pipette by mixing and transferring $100 \mu \mathrm{l}$ from row $\mathrm{B}$ to row $\mathrm{C}$. Identical serial dilutions were continued through to row $\mathrm{F}$. Test wells then received $100 \mu$ of the cell dilution, approximately yielding $1.5 \times 10^{5}$ $\mathrm{CFU} / \mathrm{ml}$. Row $\mathrm{G}$ contained alternating wells of growth controls (containing the same as the test wells without antimicrobials i.e., cells only) and sterile controls (containing the same as test wells without cells i.e., media only). Plates were sealed with Parafilm or Ziploc bags and incubated for five days at $37^{\circ} \mathrm{C}$. On day five, $50 \mu \mathrm{l}$ of 1:1 Alamar Blue (AbD Serotec, Kidlington, Oxford, UK) and 10\% v/v Tween 80 was added to one growth and one sterile control well, resealed with Parafilm or Ziploc bags and incubated in the dark. After 24 hours, if the Alamar Blue solution remained blue in the sterile well and changed to pink in the growth well, $50 \mu \mathrm{l}$ of 1:1 Alamar Blue and $10 \% \mathrm{v} / \mathrm{v}$ Tween 80 was added to all wells and incubated in the 
dark for a further 24 hours, after which results were determined spectrophotometrically. On day five the addition of Alamar blue solution to one growth and one sterile control only served as an indicator of sufficient growth and sterility, without being included in the analysis. Only wells that received the Alamar Blue solution at the same time were evaluated together. The MIC was defined as the well containing the lowest concentration of the antimicrobial where the added Alamar Blue and Tween 80 solutions corresponded to $\geq 90 \%$ prevention in Alamar Blue reduction, determined by Equation (1);

$$
\% \text { Reduction }=\frac{\left(\mathrm{O}_{2}\right.}{\left(\mathrm{R}_{1} \times \mathrm{A}_{1}\right)-\left(\mathrm{O}_{2}\right)-\left(\mathrm{R}_{2} \times \mathrm{N}_{1}\right)} \times 100
$$

Where $\mathrm{O}_{2}=$ molar extinction coefficient $(\mathrm{E})$ of oxidised Alamar Blue at $600 \mathrm{~nm} ; \mathrm{A}_{1}=$ absorbance of test wells at $570 \mathrm{~nm} ; \mathrm{O}_{1}=\mathrm{E}$ of oxidised Alamar Blue at $570 \mathrm{~nm} ; \mathrm{A}_{2}=$ absorbance of test wells at $600 \mathrm{~nm} ; \mathrm{R}_{1}=\mathrm{E}$ of reduced Alamar Blue at $570 \mathrm{~nm} ; \mathrm{N}_{2}=$ absorbance of sterile control well at $600 \mathrm{~nm} ; \mathrm{R}_{2}=\mathrm{E}$ of reduced Alamar Blue at 600 $\mathrm{nm} ; \mathrm{N}_{1}=$ absorbance of sterile control well at $570 \mathrm{~nm}$. Loss in buffer capacity for Alamar Blue was factored in by subtracting the percentage reduction for the sterile control well from the percentage reduction for the test wells. For MBC, the same method as MIC determinations was used, except that (1) concentrations investigated were $16-256 \mathrm{mg} / \mathrm{L}$, and (2) the Alamar Blue and Tween 80 solution was only added to growth and sterile control wells to monitor growth and possible contamination. For starting inoculum, cells were serially diluted in $1 \times$ PBS containing $0.05 \% \mathrm{v} / \mathrm{v}$ Tween 80 and $100 \mu \mathrm{l}$ was plated onto Middlebrook 7H10 agar containing glycerol and OADC by the pour plate method. After growth and sterility was indicated by Alamar Blue addition, $10 \mu 1$ of each test well were plated out onto Middlebrook $7 \mathrm{H} 10$ agar. CFUs were counted at three to five weeks after incubation at $37^{\circ} \mathrm{C}$. The MBC was defined as the lowest concentration causing $\geq 2 \log _{10}$ (99\% reduction in cell viability) decrease in $\mathrm{CFU} / \mathrm{ml}$ relative to the starting inoculum in the growth control wells. MIC and MBC were done in duplicate on the day, and three independent experiments were conducted. 
2.4 MIC determination by the microtiter Alamar Blue assay in the presence of pulmonary surfactant

Determination of CMS MIC in PS was adopted from Schwameis et al., [30] and Silverman et al., [31]. MIC for CMS was determined using the MABA (2.3), except that the test media in the plates contained porcine surfactant (Curosurf, Chiesi Farmaceutici SpA, Parma, Italy) to a final concentration of $1 \mathrm{mg} / \mathrm{ml}$. The MIC was defined and calculated as described (2.3). As a control, MIC was conducted in media without pulmonary surfactant. MIC was done in duplicate on the day, and three independent experiments were conducted.

\subsection{Hydrolysis of CMS to colistin as determined by UPLC}

CMS hydrolysis to colistin as determined by UPLC was adopted from Li et al., [32]. CMS and CST were incubated at $37^{\circ} \mathrm{C}$ in Sauton media using the same method as described (2.3) at their determined MIC concentrations without the presence of MTB. Samples $(600 \mu 1)$ were taken at days zero, one, and six, and were stored at $20^{\circ} \mathrm{C}$ pending analysis by UPLC. Samples $(300 \mu \mathrm{l})$ were passed through a Waters Oasis ${ }^{\circledR}$ HLB (3cc, 60mg) (Waters, Milford, MA, USA) extraction cartridges conditioned with $1 \mathrm{ml}$ methanol (Sigma-Aldrich; HPLC grade) and equilibrated with $1 \mathrm{ml}$ carbonate buffer (pH 10) (Fluka; HPLC grade). FMOC-Cl (100 $\mu 1,30 \mathrm{mM})$ (Sigma-Aldrich; HPLC grade) was reacted on the extraction column for ten minutes and the FMOC-colistin derivatives were eluted using $900 \mu \mathrm{l}$ of tetrahydrofuran (THF) (Sigma-Aldrich; HPLC grade) into Eppendorf Protein LoBind tubes using a vacuum manifold and disposable flow control valve liners (Supelco, Bellefonte, PA, USA), and mixed with $600 \mu 1$ of $0.2 \mathrm{M}$ boric acid (Sigma-Aldrich; ACS grade). UPLC analysis was performed on a Waters ACQUITY UPLC H-Class system (Waters, Milford, MA, USA) equipped with a binary solvent delivery pump, an auto sampler, and a photodiode array detector (PDA) controlled by Empower-3 software. Colistin was assayed using a Waters (Milford, MA) Acquity UPLC BEH $\mathrm{C}_{18} 1.7 \mu \mathrm{m}$ $2.1 \times 50 \mathrm{~mm}$ column at $40^{\circ} \mathrm{C}$ with the PDA detection set at $265 \mathrm{~nm}$. An isocratic mobile phase of acetonitrile-THF- $\mathrm{dddH}_{2} \mathrm{O}(87: 4: 13[\mathrm{v} / \mathrm{v}])$ was pumped at a flow rate of $0.3 \mathrm{ml} / \mathrm{min}$. Injection volumes of $10 \mu \mathrm{l}$ were used, and quantification was 
conducted by combining the areas of colistin A and colistin B; the main components of CST. Standard curves $\left(\mathrm{R}^{2}>0.98\right)$ were constructed using CST $(2-16 \mathrm{mg} / \mathrm{L})$ and as a control, CST (16 mg/L) was injected every ten injections to confirm system stability. The run time was five minutes.

\subsection{Synergy activity investigation of CMS with INH and RIF}

Synergy investigations using a modified checkerboard MABA were adopted from Bhusal et al., [33] and Caleffi-Ferracioli et al., [34]. Culture, antimicrobials, media and 96-well microtiter plates were prepared as described (2.3) except for certain differences. For three-dimensional investigations, CMS (0.25-32 mg/L) was serially diluted along the $\mathrm{x}$-axis, RIF (0.0001-0.0032 mg/L) was serially diluted along the $\mathrm{y}$ axis and as an overlay (z-axis), INH (0.008-0.064 mg/L) concentrations were dispensed over all wells of four separate plates. Two-dimensional investigations were also investigated with CMS (0.25-32 $\mathrm{mg} / \mathrm{L})$ serially diluted along the $\mathrm{x}$-axis, with RIF (0.0001-0.0032 mg/L) or INH (0.002-0.064 mg/L) serially diluted along the y-axis. As a control for INH and RIF, INH (0.0005-0.064 mg/L) was serially diluted along the $\mathrm{x}$-axis while RIF (0.0001-0.0032 mg/L) was serially along the $\mathrm{y}$ axis. Column 11 contained growth controls (containing the same as the test wells without antimicrobials i.e., cells only) and column 10 contained sterile controls (containing the same as test wells without cells i.e., media only) in all plates. Plates were inoculated with 1.5 x $10^{5} \mathrm{CFU} / \mathrm{ml}$ MTB H37Ra, sealed with Parafilm or Ziploc bags and incubated at $37^{\circ} \mathrm{C}$ for five days. After five days, the same strategy of MIC ( $\geq 90 \%$ prevention in Alamar Blue reduction) determination using Alamar Blue was used, and synergy calculations were conducted using $\sum$ FIC $[33,34]$, where the definition of synergy was; synergy $<0.5$, indifference was $0.5-4$ and antagonism was $>4$. Synergy investigations were conducted using three independent experiments.

\subsection{Time-kill assay}

Time-kill assay was adopted from Bhusal et al., [33] and de Steenwinkel et al., [35]. The best results of antimicrobial combinations determined from synergy studies were investigated using the time-kill assay. Combinations of antimicrobials, Sauton 
media and preparation of microtiter plates were prepared (2.3). Cultures (1.5 x $10^{5}$ $\mathrm{CFU} / \mathrm{ml}$ ) were prepared (2.1) and incubated with the relevant synergistic antimicrobial combination. Row $\mathrm{G}$ in the microtiter plates contained alternating growth and sterile controls for each antimicrobial combination test. Plates were sealed with either Paralfilm or in Ziploc bags and incubated at $37^{\circ} \mathrm{C}$. Part of the culture was collected on day zero, one, two, three and six for CFU determinations by serial dilution in $1 \mathrm{x}$ PBS containing $0.05 \%$ v/v Tween 80 and plating out $100 \mu 1$ of each dilution using the pour plate method with Middlebrook 7H10 agar. Agar plates were incubated for three to five weeks and colonies were counted every week until no more increase was determined to occur.

\subsection{Ultrastructure analysis of M. tuberculosis treated with CMS}

Ultrastructure investigations were adopted from Rivas-Santiago et al., [36,37]. TEM was used to investigate the mechanism of action CMS and would have on the ultrastructure of MTB. MIC was determined according MABA (2.3), but adopted from Carroll et al., [38] using $1 \times 10^{7} \mathrm{CFU} / \mathrm{ml}$, as increased cell titres were required for a workable cell pellet. MIC was determined after four days of incubation and was defined as the last well that prevented a pink color change for Alamar Blue. Once MIC was determined for the increased cell titres, MTB H37Ra was incubated in concentrations of 16 (determined MIC), 64 and $256 \mathrm{mg} / \mathrm{L}$ of CMS and CST (as a control) for 24 hours to determine the effect on the ultrastructure of MTB. After 24 hours, cells suspensions $(1 \mathrm{ml})$ were removed and centrifuged at $10000 \mathrm{~g}$ 's for one minute. The supernatant was then removed, and the pellet was fixed for one hour at room temperature using $2.5 \% \mathrm{v} / \mathrm{v}$ formaldehyde and glutaraldehyde in $0.1 \mathrm{M}$ PIPES (Merck) (pH 7 - 7.2), supplemented with $5 \mathrm{mM} \mathrm{CaCl}_{2}, \mathrm{MgCl}_{2}$ and $0.1 \%$ w/v ruthenium red (EMD Millipore) [18]. Pellets were then rinsed using PIPES buffer (3 $\mathrm{x}$ ten minutes) followed by fixation in $1 \% \mathrm{w} / \mathrm{v} \mathrm{OsO}_{4}$ (aq) (SPI Supplies, Philadelphia, USA) and rinsing with PIPES as described. Pellets were then dehydrated using ethanol (EtOH) (30, 50, 70, 90 and $3 \times 100 \%)$ for ten minutes each. After dehydration, samples where infiltrated using 1:1 EtOH and SPI-Pon 812 (SPI Supplies) for one hour, followed by $100 \%$ SPI-Pon 812 for four hours. Pellets were then polymerised at $60^{\circ} \mathrm{C}$ for 36 hours, reorientated in embedding moulds and 
polymerised for a further 36 hours in $100 \%$ SPI-Pon 812. Samples were sectioned to gold reflectance using a Reichert Ultracut E Ultramicrotome (Vienna, Austria) and collected on $\mathrm{Cu}$ formvar coated grids. Samples were post stained using uranyl acetate (three min), rinsed using $\mathrm{dH}_{2} \mathrm{O}$, stained with lead citrate (five min) and rinsed once again using $\mathrm{dH}_{2} \mathrm{O}$. Once grids were dry, samples were viewed using a Jeol 2100F TEM.

\subsection{Statistical analysis}

Statistical analysis was conducted using JMP® Pro 11.0.0 (64 bit) software copyright $(C$ 2013 SAS institute Inc. One way ANOVA was conducted, and means were compared using Student's t-test for all statistical analysis.

\section{Results and Discussion}

Sauton media was used as the test media of choice. It was suspected that 7H9 OADC would antagonise the polymyxins mechanism of action, producing a false MIC and MBC for the following reasons; (1) OADC (oleic acid, albumin [BSA], dextrose, catalase) enrichment: polymyxins and BSA form complexes [39], antagonising it's affect; (2) presence of $\mathrm{Mg}^{2+}$ and $\mathrm{Ca}^{2+}$ antagonise the effect of polymyxins [40, 41], and it was important to use physiological concentrations of divalent cations [42] for the most accurate MIC representation; (3) $\mathrm{Na}^{+}$(at $100 \mathrm{mM}$, present in OADC media) antagonises the effect of cationic antimicrobial peptides $[43,44]$ (this might not apply to polymyxins [45]); (4) it has been proposed that polymyxins also induce cell death through hydroxyl radical production i.e., Fenton reaction [46], and the presence of catalase in OADC would antagonise this mechanism of action.

For MIC (Table 1) and MBC data, CMS was 16 and $256 \mathrm{mg} / \mathrm{L}$ and CST was 16 and 64 $\mathrm{mg} / \mathrm{L}$ respectively. CMS was expected to have a higher MIC than CST, since CMS is a prodrug of colistin and never fully converts to it's active form [32]. Depending on the manufacturer and test conditions, a maximum of 60-80\% of CMS might convert to colistin. However, according to UPLC analysis conducted using the MIC determined for CMS and CST (16 mg/L), starting concentrations of colistin (elution 
Table 1

MIC results for CMS, RIF and INH are displayed in the upper tier, while the bottom tier

\begin{tabular}{|c|c|c|c|c|}
\hline & CMS (mg/L) & $\mathrm{RIF}(\mathrm{mg} / \mathrm{L})$ & INH (mg/L) & \\
\hline Determined MIC & 16 & 0.0032 & 0.064 & \\
\hline Synergy combination & & & & $\sum \mathrm{FIC}$ \\
\hline 1 & 4 & 0.0004 & 0.064 & 1.375 \\
\hline 2 & 16 & 0.0016 & 0.032 & 2.000 \\
\hline 3 & 16 & 0.0032 & 0.016 & 2.080 \\
\hline 4 & 16 & 0.0032 & 0.008 & 2.125 \\
\hline 5 & 16 & 0.0032 & - & 2.000 \\
\hline 6 & 2 & - & 0.064 & 1.125 \\
\hline 7 & - & 0.0032 & 0.064 & 2.000 \\
\hline
\end{tabular}


of colistin $\mathrm{A}=1.9 \mathrm{~min}$ and colistin $\mathrm{B}=2.2 \mathrm{~min}$ ) at day zero were $0 \mathrm{mg} / \mathrm{L}$ for CMS and $15.97 \pm 1.79 \mathrm{mg} / \mathrm{L}$ for CST. After 24 hours incubation, CMS had converted to $15.86 \pm 2.75 \mathrm{mg} / \mathrm{L}$ colistin (99\% conversion) and CST had a colistin concentration of $14.80 \mathrm{mg} / \mathrm{L} \pm 2.39 \mathrm{mg} / \mathrm{L}$. This indicated similar concentrations of colistin were delivered to MTB explaining the similar MICs. After six days of incubation, there was no statistical significant difference between concentrations of colistin after 24 hours and at day six of incubation for CMS and CST. The first 24 hours of incubation are hypothesised to be important in reduction of MTB cell viability. CMS is in the process of hydrolysis within the first 24 hours of incubation, compared to CST which is added in its active form. This could explain the higher concentration of CMS (256 mg/L) required to cause a $99 \%$ reduction in viable MTB cells.

As mentioned by Rastogi et al., [20], the MIC and MBC for CST, and CMS (determined in this publication) against MTB remain much higher than that achievable in serum during treatment and raise concerns of systemic toxicity [6]. However, inhaled CMS is commonly used in patients with cystic fibrosis and Ratjen et al., [47] determined the pharmacokinetics of inhaled colistimethate-Na (CMS) (administered using a nebulizer) in cystic fibrosis patients. Local concentrations in sputum were much higher than that of systemic concentrations. Maximum sputum concentrations $(\sim 40 \mathrm{mg} / \mathrm{L})$ were ten times higher than the MIC breakpoint for $P$. aeruginosa proposed by the BSAC. After 12 hours, mean colistin concentrations were still above $4 \mathrm{mg} / \mathrm{L}$. Thus, inhalation of CMS dry powder could possibly lead to concentrations well above the determined MICs in the proximal airways [52], especially when used polytherapeutically.

For the MIC in PS, reduction in Alamar Blue for CMS was $95 \pm 5 \%$, which corresponded to a MIC value of $128 \mathrm{mg} / \mathrm{L}$. This is consistent with the findings of Schwameis et al., [30], since the authors determined that at concentrations 64 times the determined MIC for CST against $P$. aeruginosa, the inhibitory effects of PS were overcome. When compared to the MIC determined in the absence of PS, the CMS concentrations required to be increased eight times to overcome the inhibitory effect of PS, producing the same percentage of Alamar Blue reduction. Thus, CMS is antagonised by the presence of PS. Antagonism is due to CMS forming complexes with PS in a similar way that CMS would form complexes with phospholipids [30]. Inhalation of dry powder CMS might overcome the inhibitory effects of PS [52]. 
Table 1 displays the best combinations of CMS, RIF and INH determined from synergistic investigations. The best combinations were determined using the lowest antimicrobial MIC that resulted in $\mathrm{a} \geq 90 \%$ prevention in Alamar Blue reduction. All combinations revealed a $\sum$ FIC between 0.5-4 indicating indifference when using CMS in combinations with INH and RIF. CMS (2 mg/L) and INH (0.064 mg/L) displayed the lowest $\sum$ FIC with 1.125. The combinations with the lowest $\sum$ FIC were further investigated with a time-kill assay to observe if there was a faster killing effect or a greater killing effect on the viable MTB cells present during incubation. Strangely, CST is highly synergistic with RIF against gram-negative organisms [4850], but this is opposite for Mycobacteria. Previous drug enhancement studies for Mycobacterium avium [51] revealed similar results as we determined for CMS against MTB. The authors [51] observed no enhancement of drug activity for CST with RIF or INH, but no antagonism was observed either.

Figure 1 displays the results of the time-kill assay using the best combinations determined from the synergy the study according to $\sum$ FIC. The only statistical difference in kinetic killing was for the combination of RIF $(0.0032 \mathrm{mg} / \mathrm{L})+\mathrm{INH}$ $(0.064 \mathrm{mg} / \mathrm{L})$ at day one of incubation indicating a faster rate within 24 hours. After six days of incubation, CMS (2 mg/L) + INH (0.064 mg/L) caused a $>2 \log _{10}$ $\mathrm{CFU} / \mathrm{ml}$ reduction in cell viability (> $99 \%$ reduction) and this was statistically different from all other combinations. A reduced killing effect was observed when CMS is used together with RIF, compared to CMS and INH. Thus, it was determined that the best combination to use would be that of CMS and INH (additive effect). To our knowledge, no such interaction of CMS together with INH against MTB has been reported and an attempt was made to try to understand this mechanism of action by use of TEM.

For TEM investigations, control MTB cells revealed to have lipid inclusions, a welldefined cytoplasmic membrane and a thin, slightly electron lucent outer polysaccharide membrane (Figure 2A, B). At low concentrations of CMS and CST $(16 \mathrm{mg} / \mathrm{L})$ (Figure 2C, D), increased amount of mesosomes were observed within the MTB cells with slight disruption to majority of MTB cells. At higher concentrations (64 mg/L) (Figure 2E, F), increased amount of mesosomes were also observed, in addition to a patchy, thicker, and more electron dense outer polysaccharide layer. Budding from the outer polysaccharide was also observed. At the highest 


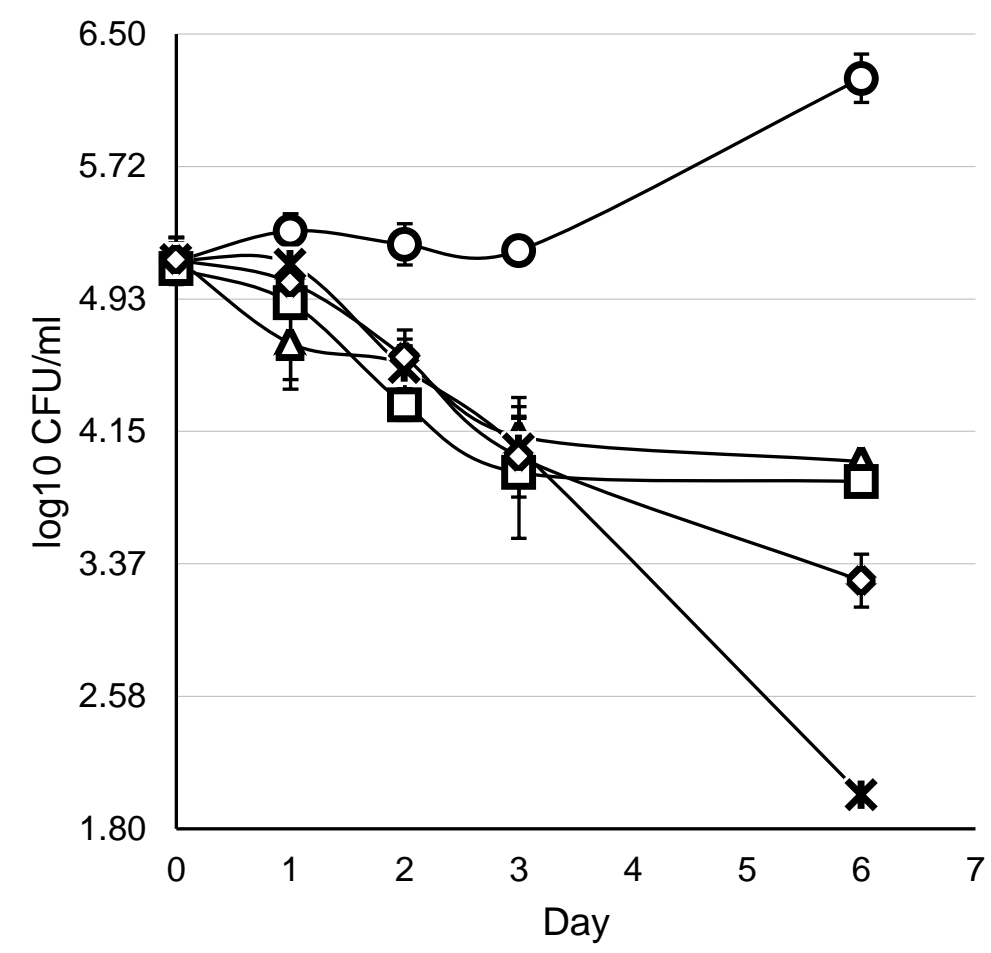

Figure 1. Time-kill assay displaying $\log _{10} \mathrm{CFU} / \mathrm{ml}$ vs day with control (circle), RIF $(0,0032 \mathrm{mg} / \mathrm{L})+$ INH (0,064 mg/L) (triangle), CMS (2 mg/L) + INH (0,064 mg/L) (cross), CMS (16 mg/L) + RIF $(0,0032 \mathrm{mg} / \mathrm{L})$ (square), CMS (4 mg/L) + INH (0,064 mg/L) + RIF (0,0004 mg/L) (diamond). Error bars display standard deviation. 


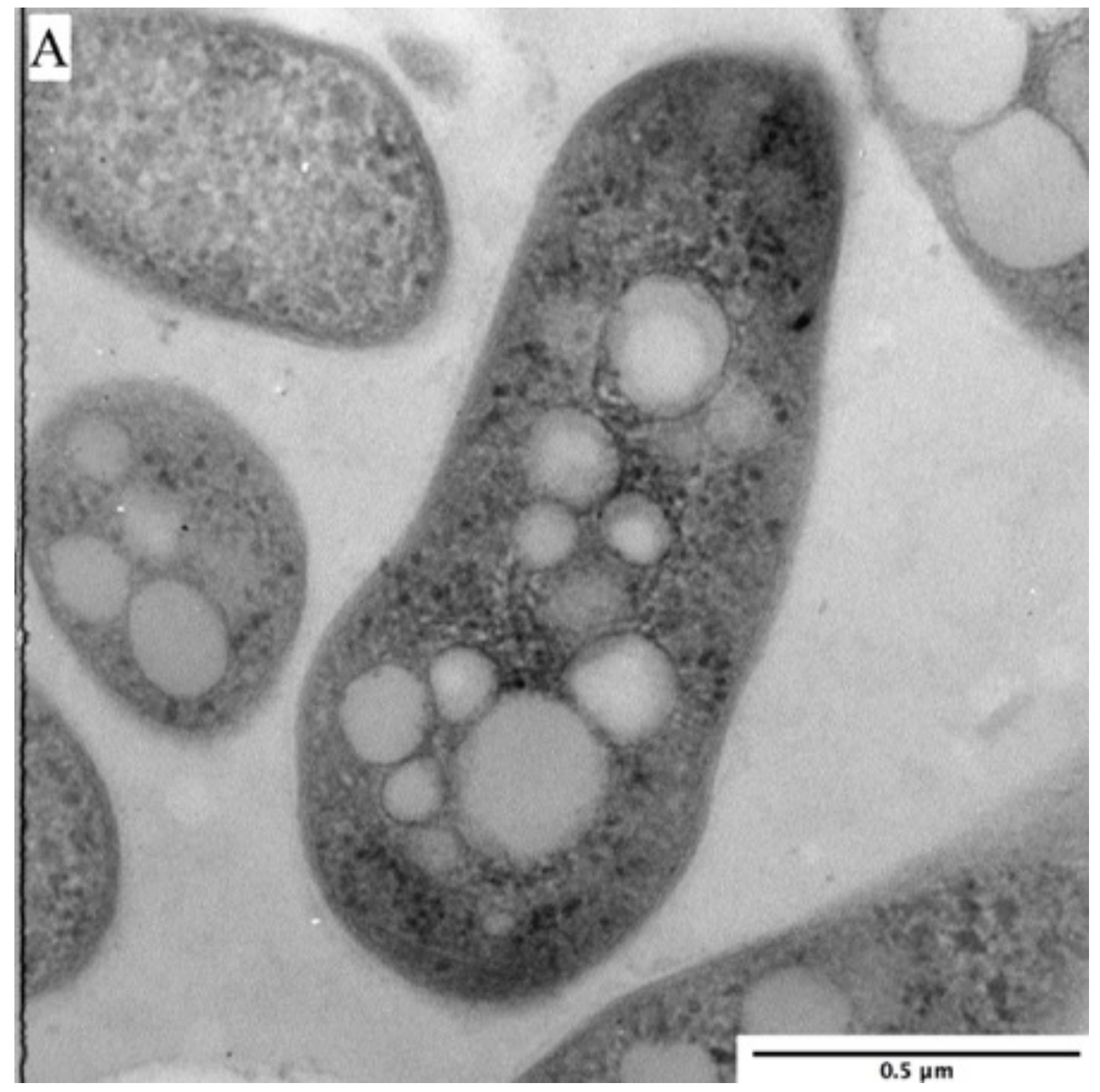




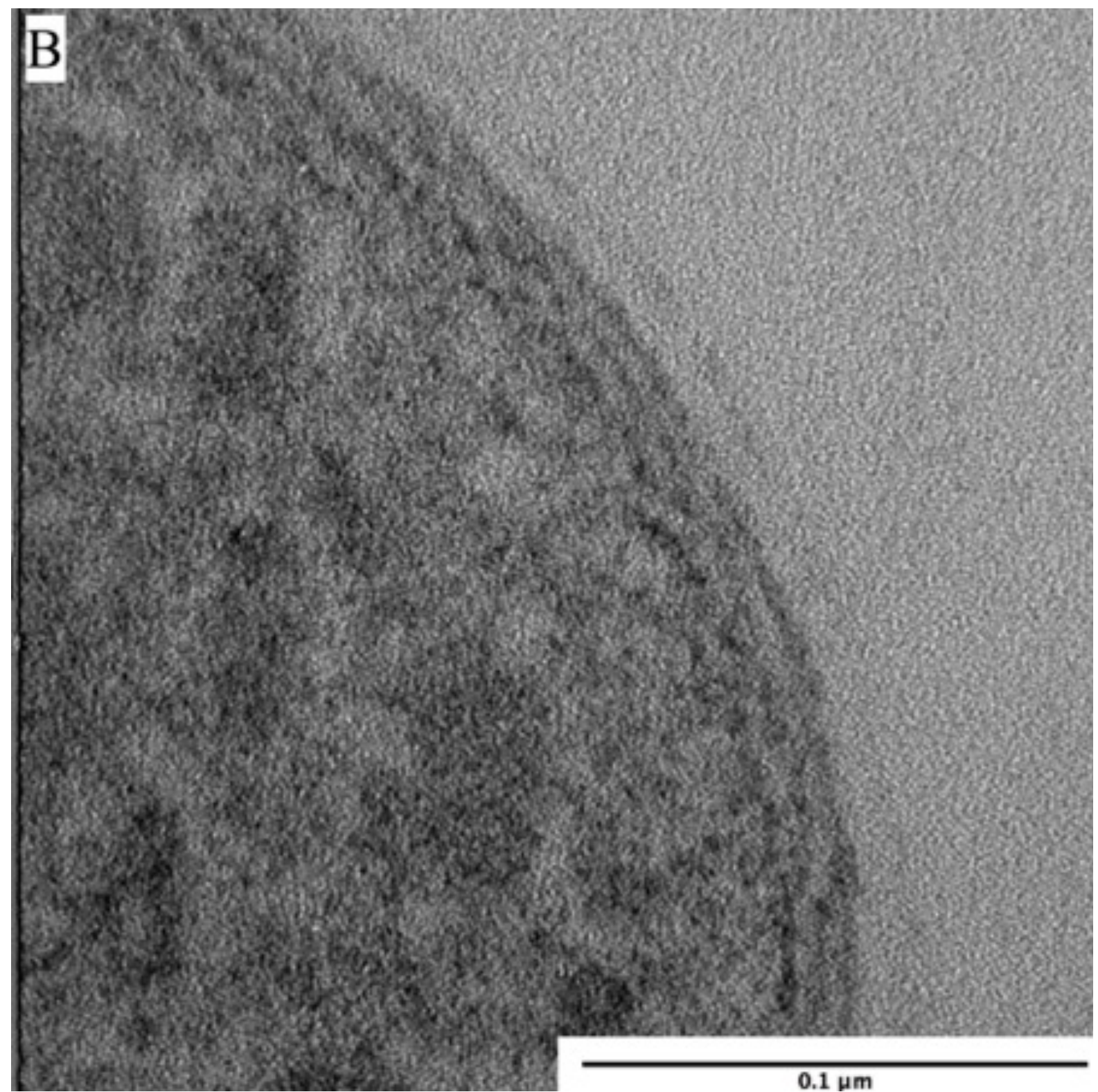




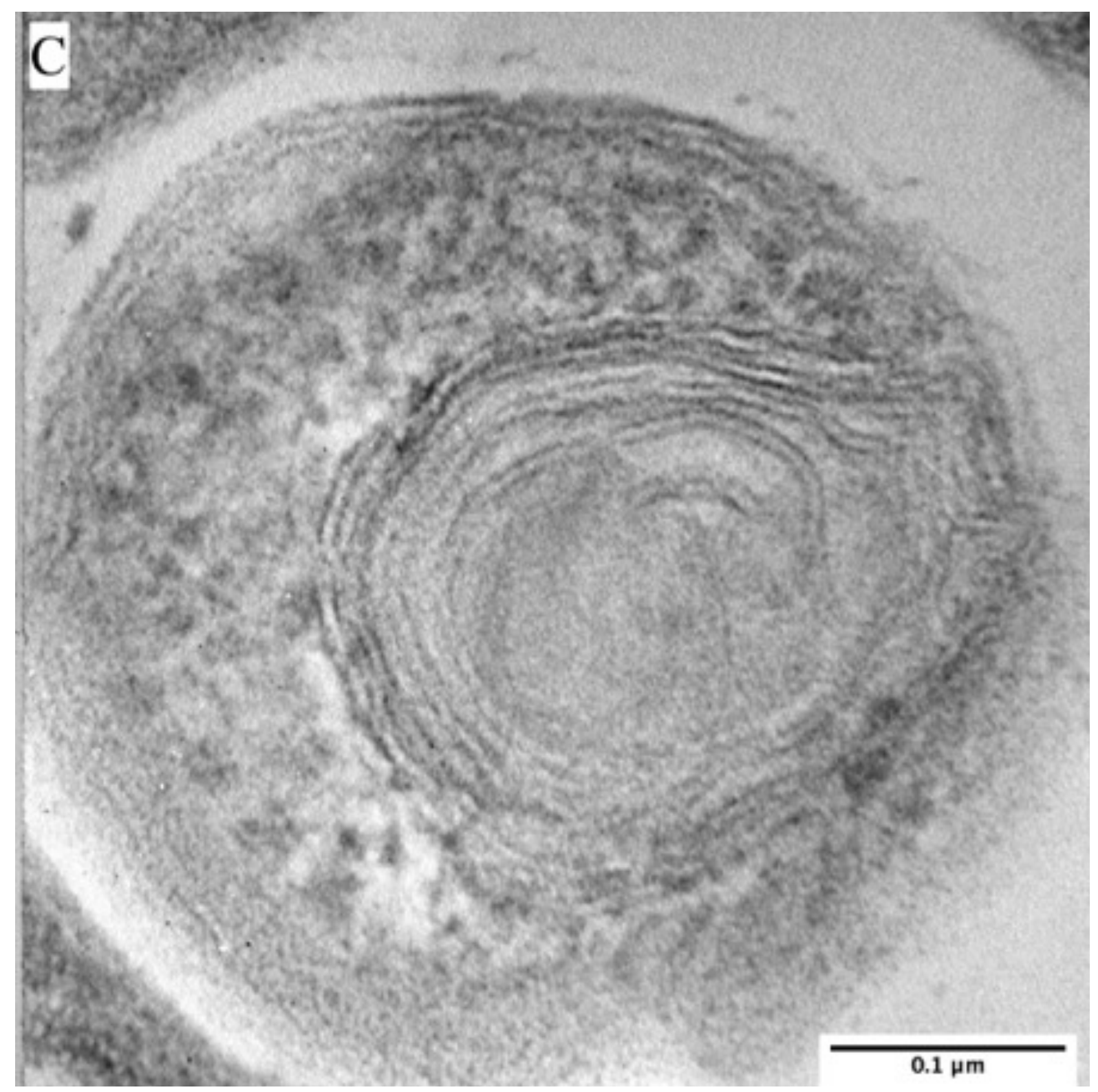




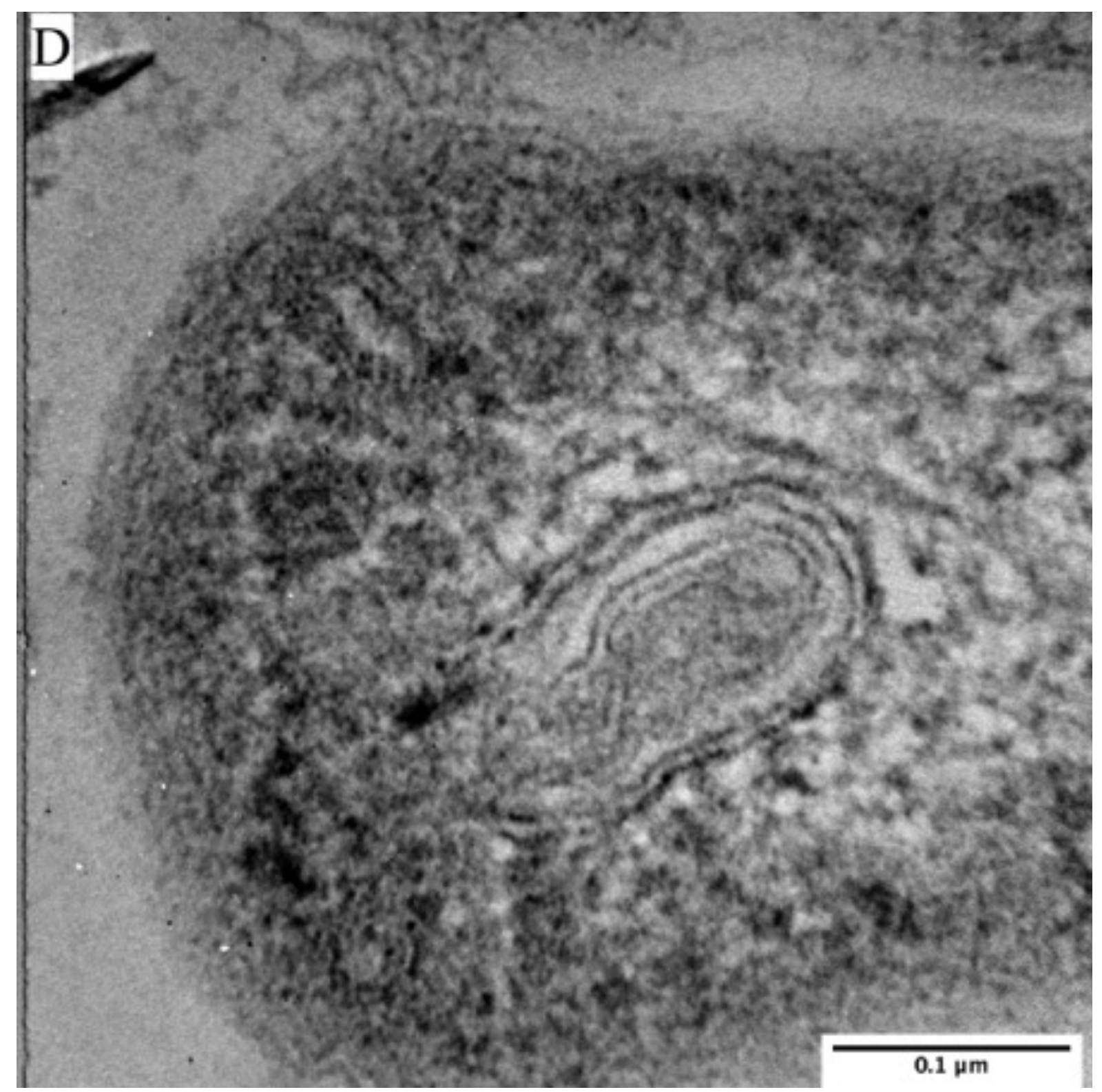




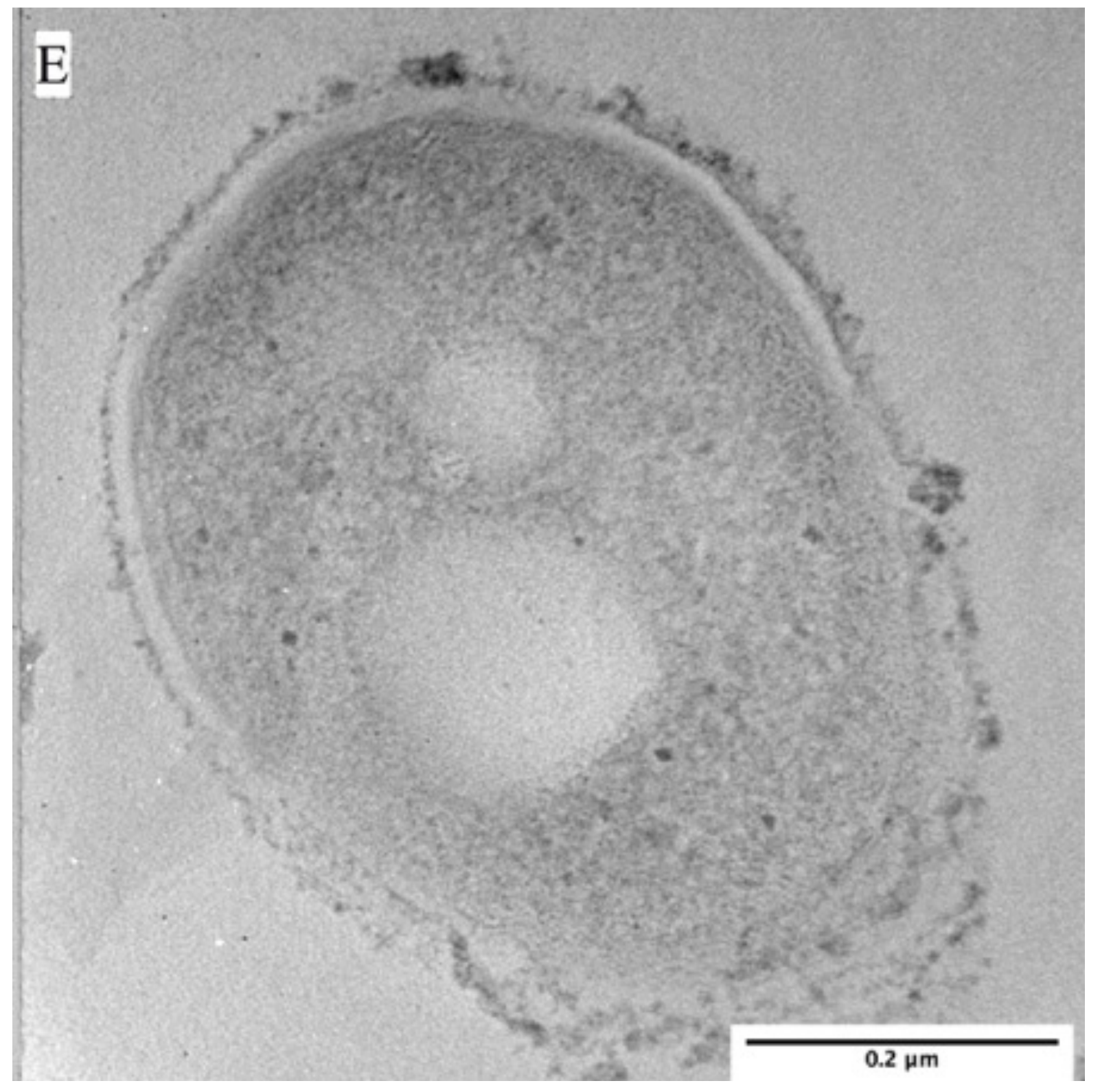




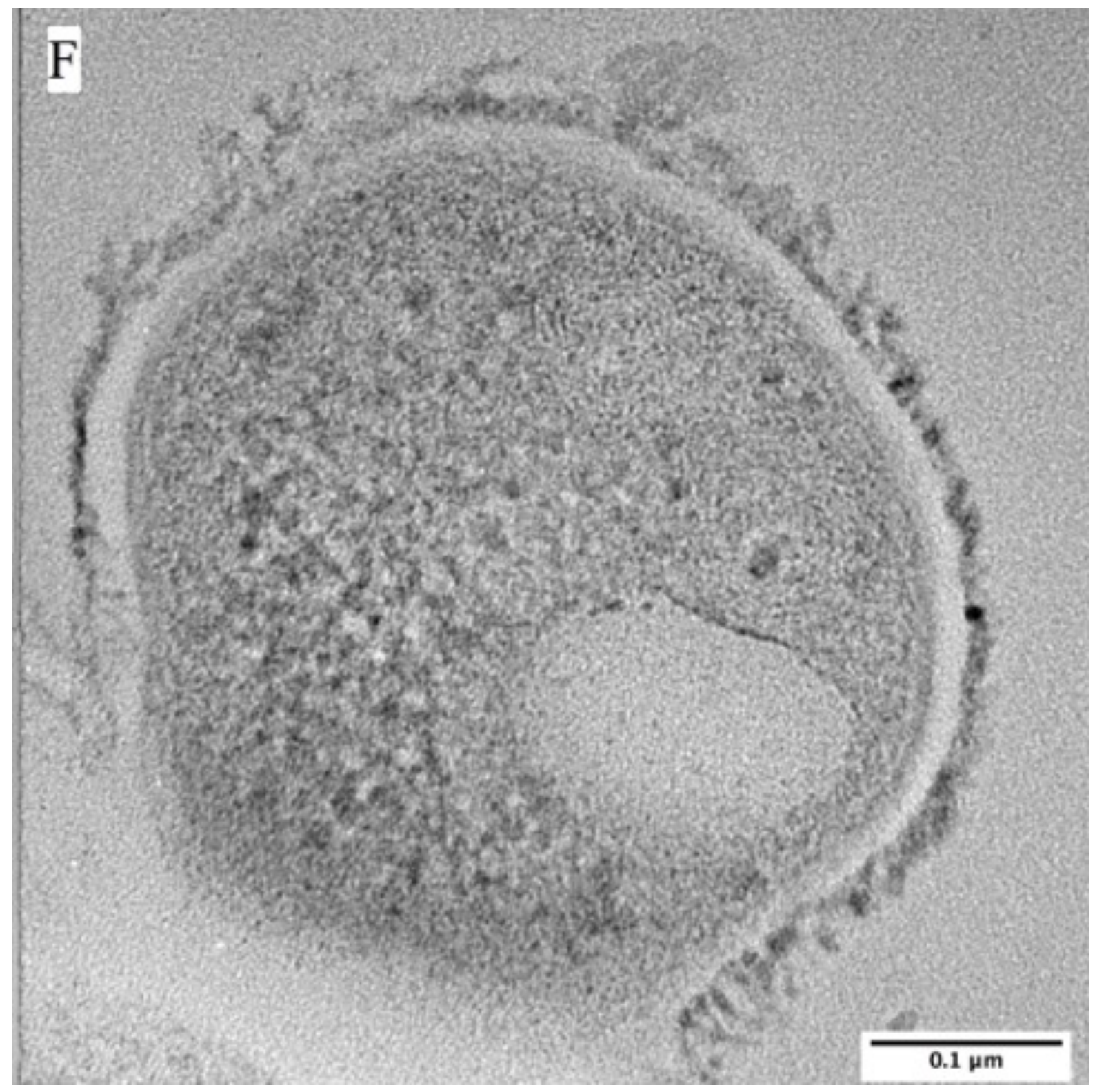




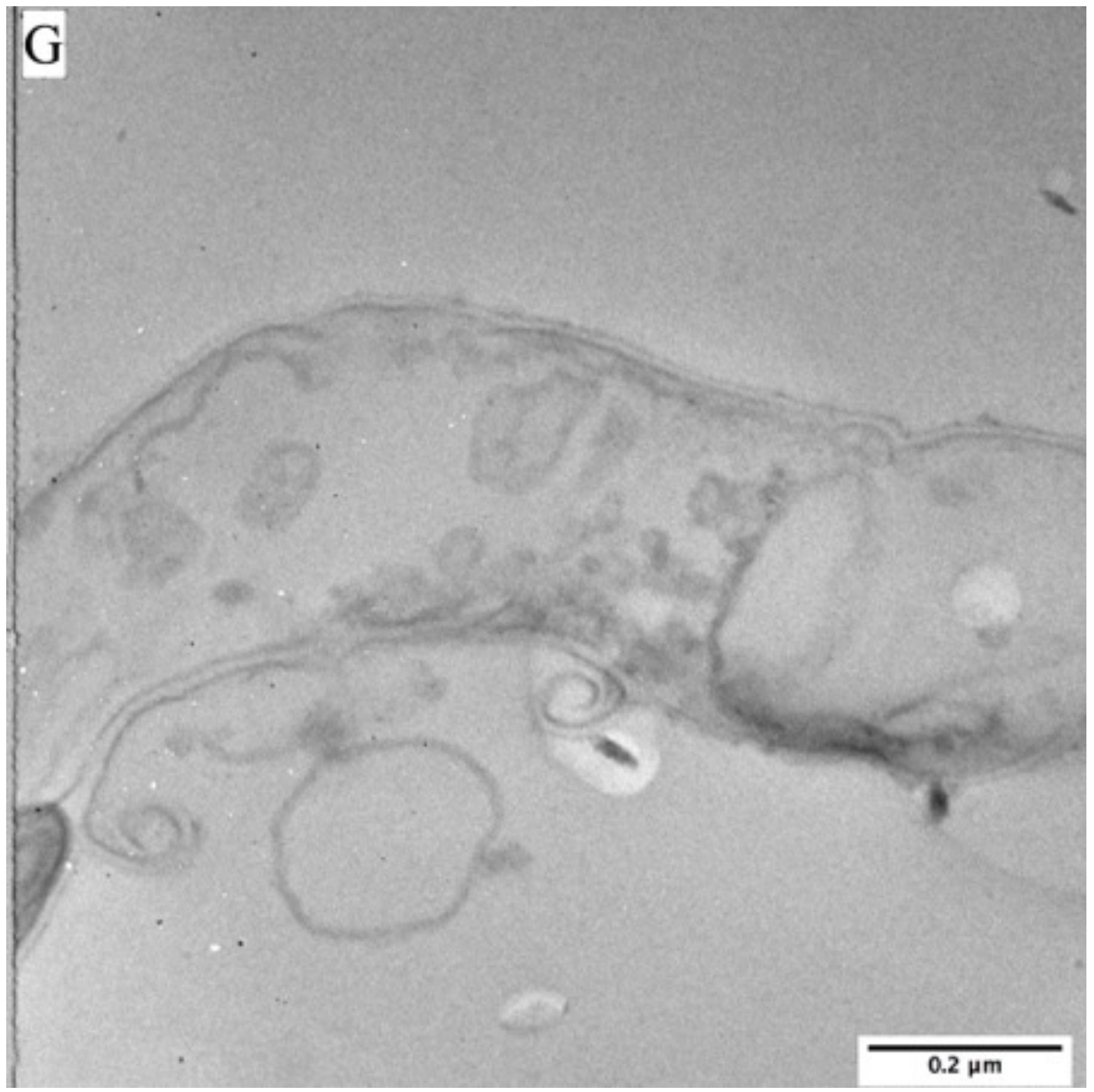




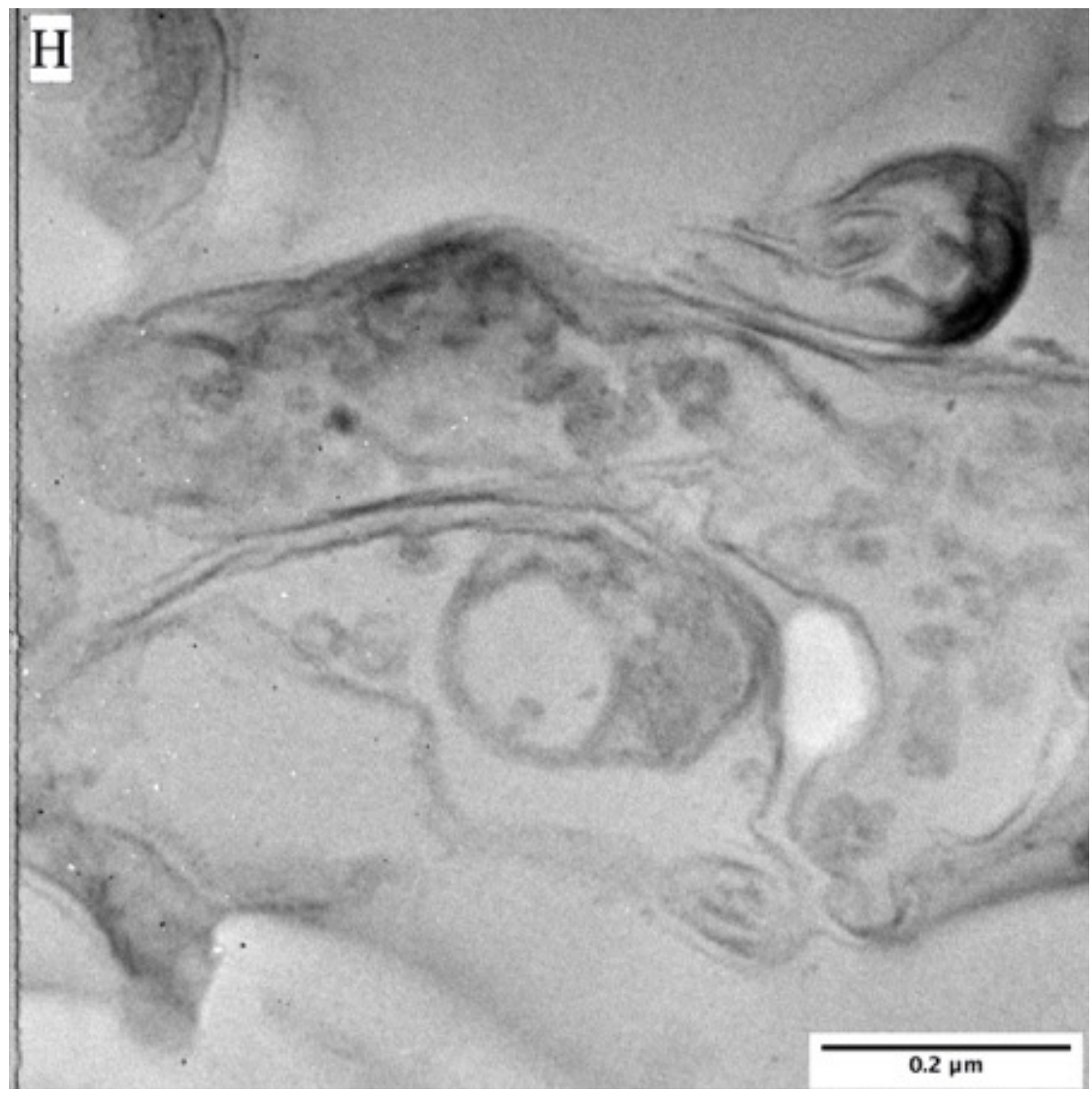

Figure 2. Effect of various CMS and CST concentrations on the ultrastructure of M. tuberculosis H37Ra after 24 hours incubation at $37^{\circ} \mathrm{C}$. (A) Control, (B) control, (C) CMS $16 \mathrm{mg} / \mathrm{L}$, (D) CST $16 \mathrm{mg} / \mathrm{L}$, (E) CMS $64 \mathrm{mg} / \mathrm{L}$, (F) CST $64 \mathrm{mg} / \mathrm{L}$, (G) CMS $256 \mathrm{mg} / \mathrm{L}$, (H) CST $256 \mathrm{mg} / \mathrm{L}$. Scale bar (A) $0.5 \mathrm{~mm}$, (B) $0.1 \mathrm{~mm}$, (C) $0.1 \mathrm{~mm}$, (D) $0.1 \mathrm{~mm}$, (E) $0.2 \mathrm{~mm}$, (F) $0.1 \mathrm{~mm}$, (G) $0.2 \mathrm{~mm}$, (H) $0.2 \mathrm{~mm}$. 
concentration tested $(256 \mathrm{mg} / \mathrm{L}$ ) (Figure 2G, H), increased effects that have been described were observed in addition to a large amount of cell lysis and cell debris present. CMS and CST share similar mechanisms of action within 24 hours since both have delivered similar amounts of colistin to the cells as determined by UPLC analysis. Similar results have been observed for David et al., [18], where exposure of M. aurum exposure to CST (50 and $100 \mathrm{mg} / \mathrm{L}$ ) demonstrated cytoplasmic membrane injuries, patchy appearance of the outer polysaccharide layer and some cell lysis. By use of various CST concentrations, it was concluded that colistin directly interacts with the cytoplasmic membrane of $M$. aurum. The authors [18] also suggested that colistin interacts with the outer polysaccharide layer, causing it to be patchy, more election dense with a budding appearance [18].

Considering the evidence obtained from the TEM investigations, it is hypothesised that colistin, formed from CMS interacts with the outer polysaccharide membrane and is then taken up by the cell via the self-promoted uptake mechanism as described by Hancock et al., [12], but after uptake, there is a response within the cell. The response is a repair mechanism causing the formation of mesosomes and thickening of the outer polysaccharide layer, in an attempt to prevent the cell from lysing. At high concentrations i.e., > $16 \mathrm{mg} / \mathrm{L}$, the amount of colistin damage is unrepairable, causing cell lysis. This hypothesis can also explain the enhanced bactericidal activity when using CMS with INH. INH is hydrophilic and can be excluded by the hydrophobic membranes of MTB. Disruption of the hydrophobic barrier can allow for an influx of INH, leading to enhanced bactericidal activity. Another possibly is that during the self-promoted uptake, INH has an enhanced uptake from the environment by the cells, once again leading to an influx within the cell and enhanced bactericidal killing [18]. The Fenton reaction [46] should be investigated an additional mechanism of action against MTB.

\section{Conclusions}

CMS alone is unsuccessful as a candidate for further drug development due to its high MIC, bacteriostatic action and an MBC/MIC ratio greater than 4. In addition, PS antagonises the effect of CMS against MTB requiring concentrations 8-fold the MIC 
$(128 \mathrm{mg} / \mathrm{L})$ to overcome the inhibitory effects but might be quashed by dry powder inhalation of CMS. Using sputum as a representation of local drug concentrations after inhalation of dry CMS powder, it was shown that $38 \%$ of patients had colistin levels $\geq 128 \mathrm{mg} / \mathrm{L}$ while the remaining $68 \%$ of patients had levels $\leq 128 \mathrm{mg} / \mathrm{L}$ [52]. Thus, it appears that even with inhalation of dry powder, CMS drug development would be unsuccessful when used as a monotherapy. However, we believe that inhalation therapy of dry powder can be further optimised to obtain better sputum levels, possibly making inhalation of dry CMS powder a better candidate for further drug development. CMS displayed a greater killing effect (additive effect) when used together with INH, likely due to disruption of the hydrophobic barrier in MTB and the self-promoted uptake of CMS and INH by MTB. Thus, the possibilities of further drug development for CMS seem better when used polytherapeutically with INH since lower concentrations of CMS are required, which could allow CMS to overcome the inhibitory effects PS at lower concentrations. When CMS was used in combination with RIF or RIF and INH, a reduced killing effect was observed as compared to CMS and INH. This can be interpreted as antagonism, thus, care needs to be taken when considering investigations of RIF with CMS. The greater killing effect of CMS and INH against MTB with regards to being used as novel treatment warrants further investigation, especially if inhalation of CMS could assist in reduction of transmission in various settings.

\section{Funding}

The University of Pretoria is thanked for funding of the project and the NRF-DAAD is thanked for financial assistance of the research which forms part of a doctoral study.

\section{Competing interests}

None.

\section{Ethical approval:}

All research was conducted with approval from The Faculty of Health Sciences 
Research Ethics Committee, University of Pretoria.

\section{Acknowledgements}

Marie Trollip from Ampath Pathology Laboratory Support Services (Centurion, Gauteng, South Africa) is thanked for all the cell culture assistance.

\section{References}

[1] WHO. 10 facts about tuberculosis.

http://www.who.int/mediacentre/factsheets/fs104/en/.

[2] WHO. Global Tuberculosis Report 2014.

http://www.who.int/tb/publications/factsheet_global.pdf?ua=1.

[3] Stansly PG, Shepherd RG, Weate HJ. Polymyxin: a new chemotherapeutic agent. Bull. Johns Hopkins Hosp 1947; 81: 43-4.

[4] Koyama Y, Kurosasa A, Tsuchiya A, Takakuta. A new antibiotic "colistin" produced by spore-forming soil bacteria. J Antibiot (Tokyo) 1950; 3: 457-8.

[5] Komura S, Kurahashi K. Partial purification and properties of L-2,4diaminobutyric acid activating enzyme from a polymyxin E producing organism. $\mathbf{J}$ Biochem (Tokyo) 1979; 86: 1013-21.

[6] Nation RL, Li J. Polymyxins. In: Grayson ML, ed. Kucers' the use of antibiotics. London: Hodder Arnold 2010; 955-70.

[7] Bergen PJ, Li J, Rayner CR, Nation RL Colistin methanesulfonate is an inactive prodrug of colistin against Pseudomonas aeruginosa. Antimicrob Agents Chemother 2006; 50: 1953-8.

[8] Li J, Coulthard K, Milne R, Nation RL, Conway S, Peckham D et al. Steady-state pharmacokinetics of intravenous colistin methanesulfonate in patients with cystic fibrosis. J Antimicrob Chemother 2003; 52: 987-92.

[9] Li J, Rayner CR, Nation RL, Deans R, Boots R, Widdecombe N et al. Pharmacokinetics of colistin methanesulfonate and colistin in a critically ill patient receiving continuous venovenous hemodiafiltration. Antimicrob Agents Chemother 
2005; 49: 4814-5.

[10] Newton BA. Reversal of the antimicrobial activity of polymyxin by divalent cations. Nature (London) 1953; 172: 160-1.

[11] Newton BA. The properties and mode of action of the polymyxins. Bacteriol Rev 1956; 20: 14-27.

[12] Hancock RE, Chapple DS. Peptide Antibiotics. Antimicrob Agents Chemother 1999; 43: 1317-23.

[13] Evans ME, Feola DJ, Rapp RP. Polymyxin B sulfate and colistin: old antibiotics for emerging multiresistant gram-negative bacterial infections. Ann Pharmacother 1999; 33: 960-7.

[14] Falagas ME, Kasiakou SK. Colistin: the revival of polymyxins for the management of multidrug-resistant gram-negative bacterial infections. Clin Infect Dis 2005; 40: 1333-41.

[15] Li J, Nation RL, Milne RW, Turnidge JD, Coulthard K. Evaluation of colistin as an agent against multi-resistant gram-negative bacteria. Int J Antimicrob Agents $2005 ; 25: 11-25$.

[16] Li J, Nation RL, Turnidge JD, Milne RW, Coulthard K, Rayner CR et al. Colistin: the re-emerging antibiotic for multidrug-resistant Gram-negative bacterial infections. Lancet Infect Dis 2006; 6: 589-601.

[17] Zavascki AP, Goldani LZ, Li J, Nation RL. Polymyxin B for the treatment of multidrug-resistant pathogens: a critical review. J Antimicrob Chemother 2007; 60: 1206-15.

[18] David HL, Rastogi N. Antibacterial action of colistin (polymyxin E) against Mycobacterium aurum. Antimicrob Agents Chemother 1985; 27: 701-7.

[19] David HL, Rastogi N, Clavel-Sérès S, Clément F. Action of colistin (polymyxin E) on the lytic cycle of the mycobacteriophage D29 in Mycobacterium tuberculosis. Zbl Bakt-Int J Med M 1986; 262: 321-34.

[20] Rastogi N, Potar MC, David HL. Antimycobacterial spectrum of colistin (polymyxin E). Ann Inst Pasteur Mic 1986; 137: 45-53.

[21] Rastogi N, Henrotte JG, David HL. Colistin (polymyxin E)-induced cell leakage in Mycobacterium aurum. Zbl Bakt-Int J Med M 1987; 263: 548-51.

[22] Rastogi N, Potar MC, Henrotte JG, Franck G, David HL. Further studies on colistin (polymyxin E)-induced cell leakage in mycobacteria: $\mathrm{Mg}^{++}$efflux in 
Mycobacterium avium and its effects on drug-susceptibility. Zbl Bakt-Int J Med M 1988; 268: 251-8.

[23] Korycka-Machała M, Ziółkowski A, Rumijowska-Galewicz A, Lisowska K, Sedlaczek L. Polycations increase the permeability of Mycobacterium vaccae cell envelopes to hydrophobic compounds. Microbiology+ 2001; 147: 2769-81.

[24] Malaviya A, Gomes J. Enhanced biotransformation of sitosterol to androstenedione by Mycobacterium sp. using cell wall permeabilising antibiotics. J Ind Microbiol Biotechnol 2008; 35: 1235-9.

[25] Mogi T, Murase Y, Mori M, Shiomi K, Omura S, Paranagama MP. Polymyxin B identified as an inhibitor of alternative NADH dehydrogenase and malate: quinone oxidoreductase from the gram-positive bacterium Mycobacterium smegmatis. $\mathrm{J}$ Biochem 2009; 146: 491-9.

[26] Larsen MH, Biermann K, Jacobs WR, Jr. Laboratory maintenance of Mycobacterium tuberculosis. Curr Protoc Microbiol 2007; Chapter 10: Unit 10A.1.

[27] Pethe K, Sequeira PC, Agarwalla S, Rhee K, Kuhen K, Yee W et al. A chemical genetic screen in Mycobacterium tuberculosis identifies carbon-source-dependent growth inhibitors devoid of in vivo efficacy. Nat Commun 2010; 1: 1-8.

[28] Collins LS, Franzblau SG. Microplate Alamar Blue assay versus BACTEC 460 system for high-throughput screening of compounds against Mycobacterium tuberculosis and Mycobacterium avium. Antimicrob Agents Chemother 1997; 41: 1004-9.

[29] Franzblau SG, Witzig RS, McLaughlin JC, Torres P, Madico G, Hernandez A et al. Rapid, low-technology MIC determination with clinical Mycobacterium tuberculosis isolates by using the microplate Alamar Blue assay. J Clin Microbiol 1998; 36: 362-6.

[30] Schwameis R, Erdogan-Yildirim Z, Manafi M, Zeitlinger MA, Strommer S, Sauermann R. Effect of pulmonary surfactant on antimicrobial activity in vitro. Antimicrob Agents Chemother 2013; 57: 5151-4.

[31] Silverman JA, Mortin LI, Vanpraagh AD, Li T, Alder J. Inhibition of daptomycin by pulmonary surfactant: in vitro modeling and clinical impact. J Infect Dis 2005; 191: 2149-52.

[32] Li J, Milne RW, Nation RL, Turnidge JD, Coulthard K. Stability of colistin and colistin methanesulfonate in aqueous media and plasma as determined by high- 
performance liquid chromatography. Antimicrob Agents Chemother 2003; 47: 136470.

[33] Bhusal Y, Shiohira CM, Yamane N. Determination of in vitro synergy when three antimicrobial agents are combined against Mycobacterium tuberculosis. Int J Antimicrob Ag 2005; 26: 292-97.

[34] Caleffi-Ferracioli KR, Maltempe FG, Siqueira VL, Cardoso RF. Fast detection of drug interaction in Mycobacterium tuberculosis by a checkerboard resazurin method. Tuberculosis 2013; 93: 660-63.

[35] de Steenwinkel JE, de Knegt GJ, ten Kate MT, van Belkum A, Verbrugh HA, Kremer K et al. Time-kill kinetics of anti-tuberculosis drugs, and emergence of resistance, in relation to metabolic activity of Mycobacterium tuberculosis. $\mathrm{J}$ Antimicrob Chemother 2010; 65: 2582-9.

[36] Rivas-Santiago B, Castañeda-Delgado JE, Rivas Santiago CE, Waldbrook M, González-Curiel I, León-Contreras JC et al. Ability of Innate Defence Regulator Peptides IDR-1002, IDR-HH2 and IDR-1018 to Protect against Mycobacterium tuberculosis Infections in Animal Models. PLOS ONE 2013; 8: e59119.

[37] Rivas-Santiago B, Rivas Santiago CE, Castañeda-Delgado JE, León-Contreras JC, Hancock RE, Hernandez-Pando R. Activity of LL-37, CRAMP and antimicrobial peptide-derived compounds E2, E6 and CP26 against Mycobacterium tuberculosis. Int J Antimicrob Ag 2013; 41: 143-8.

[38] Carroll J, Douarre P, Coffey A, Buckley J, Cashman B, O’Farrell K, O’Mahony J. Optimization of a Rapid Viability Assay for Mycobacterium avium subsp. paratuberculosis by Using Alamar Blue. Appl Environ Microb 2009; 75: 7870-2.

[39] Liu B, Yang C, Yan X, Wang J, Lv Y. Study on the conjugation mechanism of colistin sulfate with bovine serum albumin and effect of the metal ions on the reaction. J Lumin 2012; 132: 1133-8.

[40] Chen CC, Feingold DS. Locus of divalent cation inhibition of the bactericidal action of polymyxin B. Antimicrob Agents Chemother 1972; 2: 331-5.

[41] D'Amato RF, Thornsberry C, Baker CN, Kirven LA. Effect of calcium and magnesium ions on the susceptibility of Pseudomonas species to tetracycline, gentamicin polymyxin B, and carbenicillin. Antimicrob Agents Chemother 1975; 7: 596-600.

[42] Clinical and Laboratory Standards Institute. Performance Standards for 
Antimicrobial Susceptibility Testing: Sixteenth Informational Supplement M100AS16. CLSI, Wayne PA, USA, 2006.

[43] Hancock RE, Sahl HG. Antimicrobial and host-defense peptides as new antiinfective therapeutic strategies. Nat Biotechnol 2006; 24: 1551-7.

[44] Ramón-Garcia S, Mikut R, Ng C, Ruden S, Volkmer R, Reischl M et al. Targeting Mycobacterium tuberculosis and other microbial pathogens using improved synthetic antibacterial peptides. Antimicrob Agents Chemother 2013; 57: 2295-303.

[45] Newton BA. Site of action of polymyxin on Pseudomonas aeruginosa: antagonism by cations. J Gen Microbiol 1954; 10: 491-9.

[46] Sampson TR, Liu X, Schroeder MR, Kraft CS, Burd EM, Weiss DS. Rapid killing of Acinetobacter baumannii by polymyxins is mediated by a hydroxyl radical. Antimicrob Agents Chemother 2012; 56: 5642-9.

[47] Ratjen F, Rietschel E, Kasel D, Schwiertz R, Starke K, Beier H et al. Pharmacokinetics of inhaled colistin in patients with cystic fibrosis. J Antimicrob Chemother 2006; 57: 306-11.

[48] Lee HJ, Bergen PJ, Bulitta JB, Tsuji B, Forrest A, Nation RL et al. Colistin and rifampicin combination: synergistic activity against 2 multidrug-resistant Acinetobacter baumannii in an in vitro PK/PD model. Antimicrob Agents Chemother 2013; 57: 3738-45.

[49] Tascini C, Tagliaferri E, Giani T, Leonildi A, Flaming S, Casini B et al. Synergistic activity of colistin plus rifampin against colistin-resistant KPCproducing Klebsiella pneumoniae. Antimicrob Agents Chemother 2013; 57: 3990-3.

[50] Landman D, Georgescu C, Martin DA, Quale J. Polymyxins revisited. Clin Microbiol Rev 2008; 21: 449-65.

[51] Rastogi N, Seng Goh K, David HL. Enhancement of drug susceptibility of Mycobacterium avium by inhibitors of cell envelope synthesis. Antimicrob Agents Chemother 1990; 34: 759-64.

[52] Schuster A, Hailburn C, Döring G, Goldman MH. Safety, efficacy and convenience of colistimethate sodium dry powder for inhalation (Colobreathe DPI) in patients with cystic fibrosis: a randomised study. Thorax 2013; 68: 344-50 